\title{
THE SYNTHESIS AND NMR SPECTRAL ASSIGNMENTS OF 3-NITRO-4-((6- NITROBENZOTHIAZOL-2-YL)AMINO)-2H-CHROMEN-2-ONE
}

\author{
Biljana Dekić ${ }^{1}$, Niko Radulović ${ }^{2}$ Milenko Ristić ${ }^{1}$, Vidoslav Dekić ${ }^{*}$ \\ ${ }^{1}$ Faculty of Science and Mathematics, University of Priština, Kosovska Mitrovica, Serbia. \\ ${ }^{2}$ Faculty of Science and Mathematics, University of Niš, Niš, Serbia.
}

\section{ABSTRACT}

Complete assignment of the ${ }^{1} \mathrm{H}$ and ${ }^{13} \mathrm{C}$ NMR chemical shifts of new coumarin derivate was described in this paper. A new coumarin derivate was synthesized in good yield by reaction of 4chloro-3-nitrocoumarin and 6-nitrobenzothiazol-2- amine in ethyl acetate in the presence of triethylamine. The complete spectral assignment was achieved using of $1 \mathrm{D}\left({ }^{1} \mathrm{H}\right.$ and ${ }^{13} \mathrm{C}$ NMR $)$ and 2D ( ${ }^{1} \mathrm{H}-{ }^{1} \mathrm{H}-\mathrm{COSY}$, NOESY, HSQC and HMBC) NMR experiments.

Key words: coumarins, synthesis, spectral analysis, ${ }^{1} \mathrm{H}$ NMR, ${ }^{13} \mathrm{C}$ NMR, 2D NMR

\section{INTRODUCTION}

Coumarins are important group of naturally occurring compounds, usually occur as secondary metabolites present in seeds, root, and leaves of many plant species (Murray et. al., 1982), (O'Kennedy et. al., 1997). They have important effects in plant biochemistry and physiology, acting as antioxidants, enzyme inhibitors and precursors of toxic substances and involved in the actions of plant growth hormones and growth regulators, the control of respiration, photosynthesis, as well as defense against infection (Kostova, 2005). Many of coumarin derivatives, obtained from natural sources and synthesized, have been shown to possess a remarkably broad spectrum of biological activity including antibacterial (El-Agrody et. al., 2001), (Pratibha et. al., 1999), antifungal (Patonay et. al., 1984), (Shaker et. al., 1996), (ElFarargy et. al., 1991), anticoagulant (Manolov et. al., 1995), anti-inflammatory (Emmanuel-Giota et. al., 2001), antitumor (Raev et. al., 1990), (Nofal et. al., 2000) and anti-HIV activity (Xie et. al., 1999). In industry coumarins are utilized as flavoring agents in toothpastes, foods, detergents, tobaccos, alcoholic and beverages (O'Kennedy et. al., 1997). They are also used as optical brightening agents and laser dyes due to their emission properties (Zahradnik, 1992).

Considering to wide range of medicinal and physiological properties and extensive use, coumarin derivative has been intensively studied and therefore of utmost importance that the synthesis and structure determination of these compounds should be achieved by a simple and effective method.
In continuation of our previous work (Dekić et. al., 2010), (Dekić et. al., 2013), we report herein synthesis of new coumarin derivate and complete assignments of their ${ }^{1} \mathrm{H}$ and ${ }^{13} \mathrm{C}$ NMR spectral data based on a combination of $1 \mathrm{D}$ and $2 \mathrm{D}\left({ }^{1} \mathrm{H}-{ }^{1} \mathrm{H}-\mathrm{COSY}\right.$, NOESY, HSQC and HMBC) NMR experiments.

\section{EXPERIMENTAL}

\subsection{General remarks}

Melting points were determined on a Kofler hotplate apparatus and are uncorrected. HRMS(EI) spectra were recorded on a JEOL Mstation JMS 700 instrument (JEOL, Germany). The IR measurements (ATR - attenuated total reflectance) were carried out with a Thermo Nicolet model 6700 FTIR instrument. For TLC, silica gel plates (Kiesel $60 \mathrm{~F}_{254}$, Merck) were used. Visualization was affected by spraying the plates with 1:1 (v/v) aqueous sulfuric acid and then heating. All the reagents and solvents were obtained from commercial sources (Aldrich, USA; Merck, Germany; Fluka, Germany) and used as received, except that the solvents were purified by distillation.

All NMR spectra were recorded at $25^{\circ} \mathrm{C}$ in DMSO- $d_{6}$ with TMS as an internal standard. Chemical shifts are reported in ppm $(\delta)$ and referenced to TMS $(\delta \mathrm{H}=0 \mathrm{ppm})$ in ${ }^{1} \mathrm{H}$ NMR spectra or to residual DMSO $-d_{6} /{ }^{13} \mathrm{CD}_{3} \mathrm{SOCD}_{3}(\delta \mathrm{H}=2.50 \mathrm{ppm}, \delta \mathrm{C}=39.52$ $\mathrm{ppm}$ ) in heteronuclear 2D spectra. Scalar couplings are reported in Hertz. $20 \mathrm{mg}$ of sample was dissolved in 1 
$\mathrm{ml}$ of DMSO- $d_{6}$, and $0.7 \mathrm{ml}$ of the solution transferred into a $5 \mathrm{~mm}$ Wilmad, 528-TR-7 NMR tube.

The ${ }^{1} \mathrm{H}$ and ${ }^{13} \mathrm{C}$ NMR spectra of synthesized compound were recorded on a Bruker Avance III 400 MHz NMR spectrometer $\left({ }^{1} \mathrm{H}\right.$ at $400 \mathrm{MHz},{ }^{13} \mathrm{C}$ at 100 $\mathrm{MHz}$ ), equipped with a $5-\mathrm{mm}$ dual ${ }^{13} \mathrm{C} /{ }^{1} \mathrm{H}$ probe head. The ${ }^{1} \mathrm{H}$ spectra were recorded with 16 scans, $1 \mathrm{~s}$ relaxation delay, $4 \mathrm{~s}$ acquisition time, $0.125 \mathrm{~Hz}$ digital FID resolution, 51280 FID size, with $6410 \mathrm{~Hz}$ spectral width, and an overall data point resolution of 0.0003 ppm. The ${ }^{13} \mathrm{C}$ spectra were recorded with Waltz $161 \mathrm{H}$ broadband decoupling, 1024 scans, $0.5 \mathrm{~s}$ relaxation delay, $1 \mathrm{~s}$ acquisition time, $0.5 \mathrm{~Hz}$ digital FID resolution, 65536 FID size, $31850 \mathrm{~Hz}$ spectral width, and an overall data point resolution of 0.005 ppm.

Standard pulse sequences were used for 2D spectra. COSY and NOESY spectra were recorded at spectral widths of $5 \mathrm{kHz}$ in both $F 2$ and $F 1$ domains; 1 $\mathrm{K} \times 512$ data points were acquired with 32 scans per increment and the relaxation delays of $2.0 \mathrm{~s}$. The mixing time in NOESY experiments was $1 \mathrm{~s}$. Data processing was performed on a $1 \mathrm{~K} \times 1 \mathrm{~K}$ data matrix. Inverse-detected 2D heteronuclear correlated spectra were measured over 512 complex points in $F 2$ and 256 increments in $F 1$, collecting 128 (HSQC) or 256 (HMBC) scans per increment with a relaxation delay of $1.0 \mathrm{~s}$. The spectral widths were 5 and $27 \mathrm{kHz}$ in $F 2$ and $F 1$ dimensions, respectively. The HSQC experiments were optimized for $\mathrm{C}-\mathrm{H}$ couplings of 145 $\mathrm{Hz}$; the $\mathrm{HMBC}$ experiments were optimized for longrange $\mathrm{C}-\mathrm{H}$ couplings of $10 \mathrm{~Hz}$. Fourier transforms were performed on a $512 \times 512$ data matrix. $\pi / 2$ Shifted sine-squared window functions were used along $F 1$ and $F 2$ axes for all 2D spectra.

\subsection{Synthesis}

\subsubsection{Synthesis of 4-chloro-3-nitrocoumarin (3)}

4-Chloro-3-nitrocoumarin (3), was synthesized in the two reaction steps according to a previously published procedure (Kaljaj et. al., 1987). In the first reaction step, 4-hydroxycoumarin (1) was nitrated in glacial $\mathrm{AcOH}$ by $72 \%$ aqueous $\mathrm{HNO}_{3}$ to give 4hydroxy-3-nitrocoumarin (2) (scheme 1). Starting compound for the synthesis of the new coumarin derivative 4-chloro-3-nitrocoumarin (3) was prepared from 4-hydroxy-3-nitrocoumarin in the reaction with phosphorus oxychloride and $\mathrm{N}, \mathrm{N}$-dimethylformamide in the second reaction step. Melting point, IR and ${ }^{1} \mathrm{H}$ NMR spectral data were identical to those described.<smiles></smiles><smiles>CCOC(=O)[C@@H](C)CC(C)OCC</smiles>

Scheme 1. Synthesis of 3-nitro-4-((6-nitrobenzothiazol-2-yl)amino)-2H-chromen-2-one.

2.2.2. Synthesis of 3-nitro-4-((6-nitrobenzothiazol -2-yl) amino)-2H-chromen-2-one (5)

In the ethyl acetate solution of 4-chloro-3nitrocoumarin (3) (2 g, $8.8 \mathrm{mmol})$ and 6nitrobenzothiazol-2-amine (4) (1.72 g, $8.8 \mathrm{mmol})$ was added triethylamine $(2 \mathrm{ml}, 14.4 \mathrm{mmol})$ and refluxed for $2 \mathrm{~h}$. After cooling, the precipitated solid was filtered off and washed with ethyl acetate and water. Purity of the synthesized compounds was checked by TLC. The target product, 3-nitro-4-((6- 
nitrobenzothiazol-2-yl)amino)-2H-chromen-2-one (5), was obtained as yellow powder, m.p. $178-180{ }^{\circ} \mathrm{C}$, in good yield $-86 \%$.

HRMS(EI): $\mathrm{M}^{+}\left(\mathrm{C}_{16} \mathrm{H}_{8} \mathrm{~N}_{4} \mathrm{O}_{6} \mathrm{~S}\right)$ 381.0157, requires $381.0165(\Delta=-0.8 \mathrm{mmu})$.

IR (neat): $3284(\mathrm{~N}-\mathrm{H}), 3067(\mathrm{Ar}-\mathrm{H}), 2945$ and $2885(\mathrm{C}-\mathrm{H}), 1733(\mathrm{C}=\mathrm{O}), 1642(\mathrm{C}=\mathrm{C}), 1526$ and 1324 $\left(\mathrm{NO}_{2}\right), 1123,1055,966,857,751 \mathrm{~cm}^{-1}$.

\section{RESULTS AND DISCUSSION}

The new coumarin derivative, 3-nitro-4-((6nitrobenzothiazol-2-yl)amino)-2H-chromen-2-one (5) were obtained in the reaction of 4-chloro-3nitrocoumarin (3) and 6-nitrobenzothiazol-2-amine (4) in ethyl acetate, as a yellow powder in good yield of $86 \%$.

The structure of compound 5 was confirmed using IR and NMR spectroscopy, and HRMS.

The IR spectra of synthesized compound contained characteristic bands of $\mathrm{N}-\mathrm{H}$ at $3284 \mathrm{~cm}^{-1}$ and $\mathrm{Ar}-\mathrm{H}$ bond at $3067 \mathrm{~cm}^{-1}$. The strong vibration corresponding to carbonyl group appeared at $1733 \mathrm{~cm}^{-1}$. The IR absorptions due to the presence of the $\mathrm{NO}_{2}$ group appeared at 1526 and $1324 \mathrm{~cm}^{-1}$.

High-resolution electron impact mass spectrometry (HR-EIMS) of compound 5 indicated a molecular formula of $\mathrm{C}_{16} \mathrm{H}_{8} \mathrm{~N}_{4} \mathrm{O}_{6} \mathrm{~S}\left([\mathrm{M}]^{+}\right.$at $\mathrm{m} / \mathrm{z} 381.0157, \Delta=-$ $0.8 \mathrm{mmu}$ ).

The ${ }^{1} \mathrm{H}$ NMR spectrum of synthesized compound exhibited six aromatic methine signals, three doublet of doublets at 7.18, 7.91 and $8.18 \mathrm{ppm}$, one doublet at $8.77 \mathrm{ppm}$, one doublet of triplets at $7.23 \mathrm{ppm}$ and multiplet at 7.50 to $7.52 \mathrm{ppm}$ corresponding to two protons, based on the data obtained by signal integration (Fig. 1). The ${ }^{1} \mathrm{H}$ NMR spectrum also showed a broad singlet at $8.97 \mathrm{ppm}$. Due to their chemical shift this signal was assigned to proton of the secondary amino group.

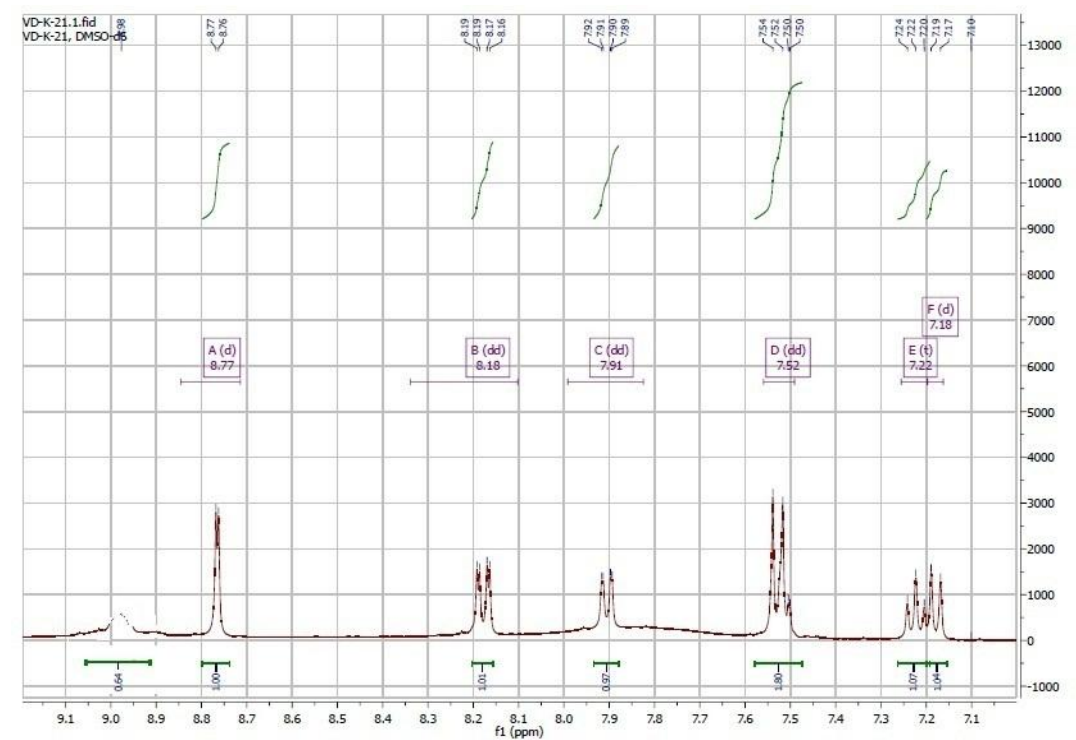

Fig. 1. The ${ }^{1} \mathrm{H}$ NMR spectrum of 3-nitro-4-((6-nitrobenzothiazol-2-yl)amino)-2H-chromen-2-on.

The cross peaks observed in the NOESY spectrum (Fig. 2) differentiated two groups of signals, one belonging to protons bonded to coumarin moiety and second corresponding to protons bonded to benzotiazole substituent. The first group of protons comprised four signals, two doublets of doublets at 7.18 and $7.91 \mathrm{ppm}$, one triplet of doublet at $7.23 \mathrm{ppm}$ and one signal from multiplet at 7.50 to $7.52 \mathrm{ppm}$, while the second group consist doublet at $8.77 \mathrm{ppm}$, doublet of doublets at $7.52 \mathrm{ppm}$, and the second signal from multiplet at 7.50 to $7.52 \mathrm{ppm}$ (Fig. 3).

From the structure of compound can be concluding that the group of four protons belongs to the coumarin moiety.

\section{Chemistry}




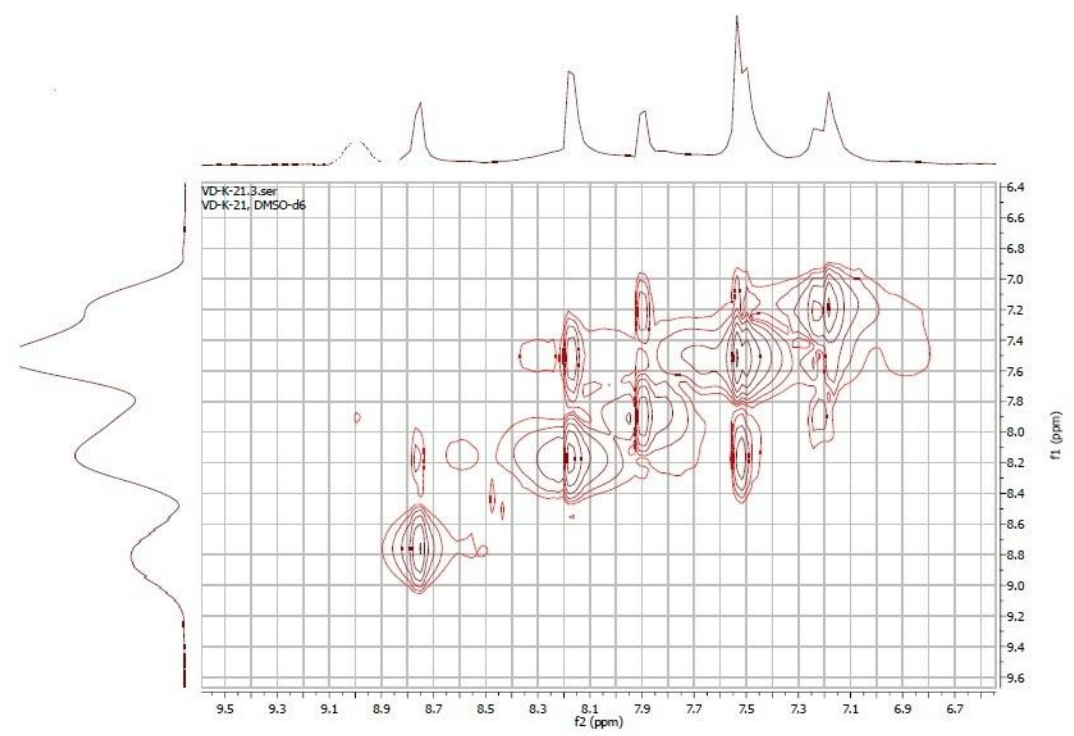

Fig. 2. The NOESY spectrum of 3-nitro-4-((6-nitrobenzothiazol-2-yl)amino)-2H-chromen-2-one.

Assignments of these signals are provided due to NOESY correlation of signal at $7.91 \mathrm{ppm}$ with the signal of the proton of the secondary amino group (8.97 ppm). This correlation assigns spatially closer $\mathrm{H}-$ 5. The assignment of H-5 is in accordance with the multiplicity of this signal due to one vicinal coupling with $\mathrm{H}-6(J=8.0 \mathrm{~Hz})$ and one long-range coupling with $\mathrm{H}-7(J=1.6 \mathrm{~Hz})$.

The rest of the protons from this group were easily assigned by their mutual NOESY correlations (Table $1)$.

The chemical shift of carbon atoms to which these protons were bonded to was subsequently determined from the HSQC spectrum (Fig. 4, Table 1).

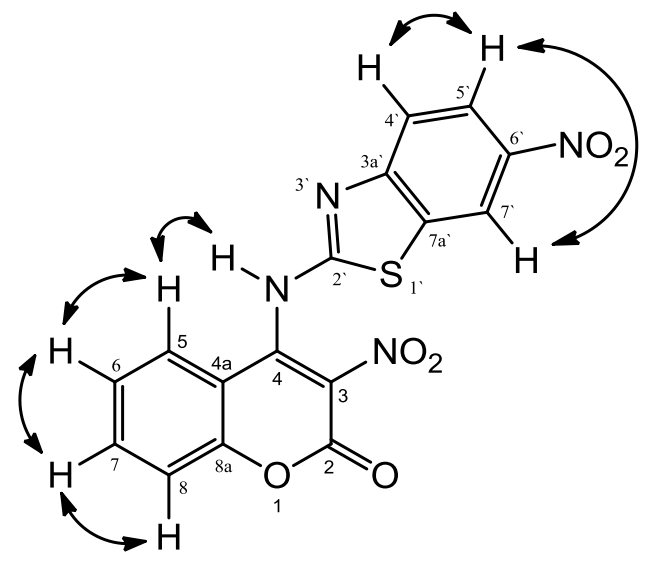

Fig. 3. The NOESY correlations of 3-nitro-4-((6nitrobenzothiazol-2-yl)amino)-2 $H$-chromen-2-one.

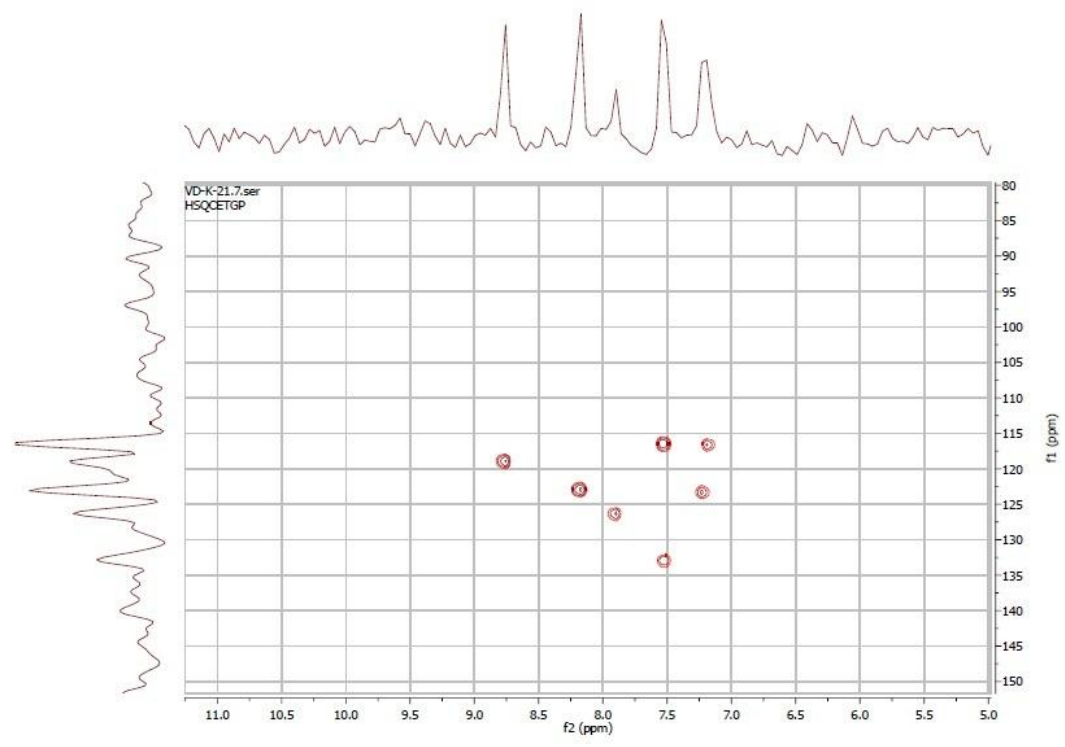

Fig. 4. The HSQC spectrum of 3-nitro-4-((6-nitrobenzothiazol-2-yl)amino)-2H-chromen-2-one.

\section{Chemistry}


The assignment of these carbons was additionally supported through HMBC correlations between $\mathrm{H}-5$ and C-7, H-6 and C-8, H-7 and C-5 and H-8 and C-6 (Fig. 5). Quaternary carbon atoms from coumarin moiety were assigned due to HMBC spectral data (Fig. $6)$. This spectrum showed simultaneous correlations of $\mathrm{H}-5$ and $\mathrm{H}-7$ with the signal at $152.9 \mathrm{ppm}$ assigned to C-8a. Mentioned carbon atom correlated with $\mathrm{H}-8$, due to characteristic interaction trough two bonds, similar to the previously studied compounds (Dekić et. al., 2010), (Dekić et. al., 2013). In a similar manner H-6 and $\mathrm{H}-8$ posses simultaneous correlations signal at 122.3 ppm assigned to $\mathrm{C}-4 \mathrm{a}$. The last three-bond correlation of H-5 with a C-signal at 167.5 ppm was assigned C-4.

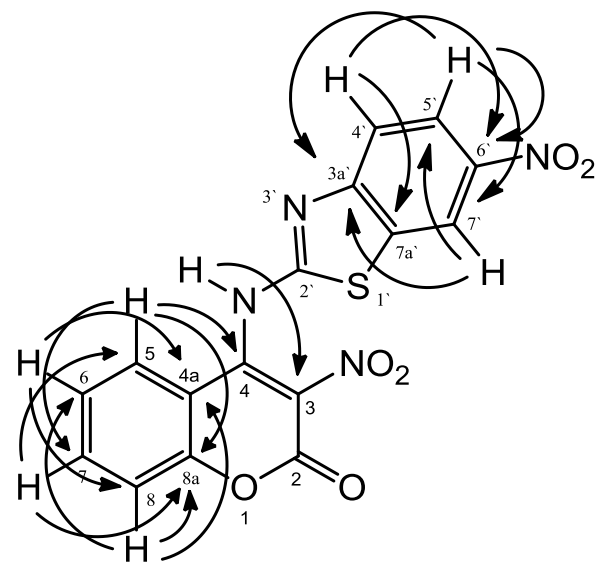

Fig. 5. The HMBC correlations of 3-nitro-4-((6nitrobenzothiazol-2-yl)amino)-2H-chromen-2-one.

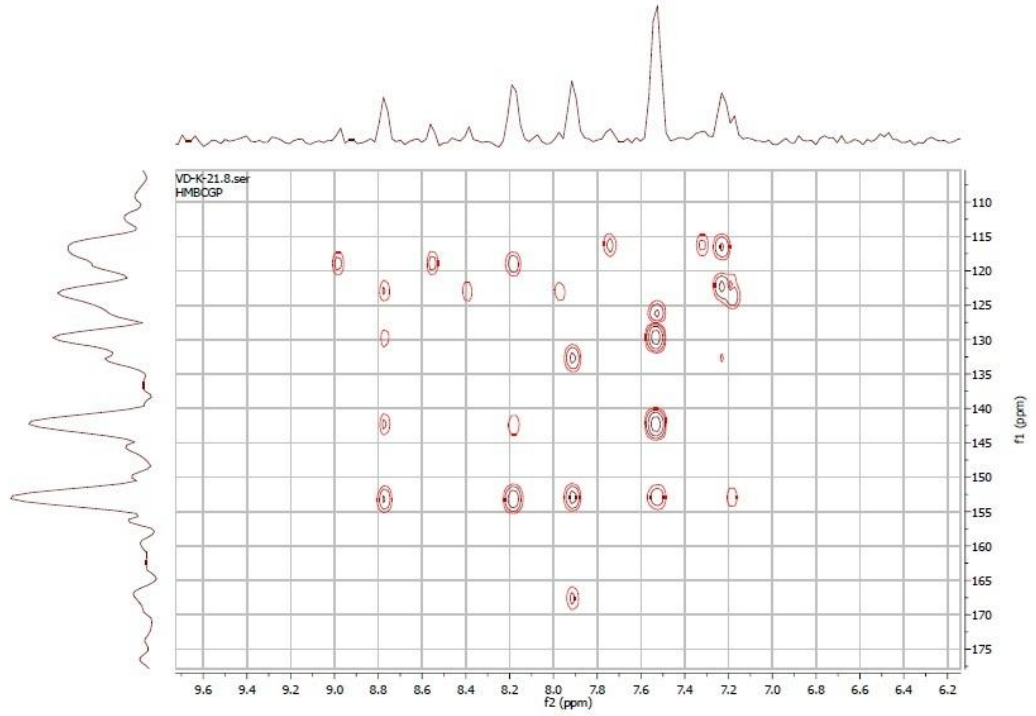

Fig. 6. The HMBC spectrum of 3-nitro-4-((6-nitrobenzothiazol-2-yl)amino)-2H-chromen-2-one.

The assignment of the aromatic methine signals of the second group was performed starting from their multiplicity and coupling constants. Simultaneous correlations of doublet of doublets at $8.18 \mathrm{ppm}$ in NOESY spectrum with the both remaining signals from this group assigned this resonance to $\mathrm{H}-5$. The rest of the aromatic protons were easily assigned due to appropriate coupling constants of $\mathrm{H}-5$ with them $(J$ $=8.8,2.4 \mathrm{~Hz}$ ). Doublet at $8.77 \mathrm{ppm}$, according to small coupling constant corresponding to longdistance coupling $(J=2.4 \mathrm{~Hz})$, were thereby assigned to H-7'. Finally, the last aromatic proton signal which observed in the multiplet at 7.50 to $7.52 \mathrm{ppm}$, were attributed to H-4'. The chemical shift of the carbons to which these protons were bonded to was subsequently determined from the HSQC spectrum (Table 1).

The assignment of quaternary carbon atoms was performed starting from the correlations in HMBC spectrum. H-4' and $\mathrm{H}-5$ ' showed through space interactions with carbon at $142.3 \mathrm{ppm}$ assigned to C6', wherein $\mathrm{H}-5$ ' coupled through two bonds. The HMBC spectrum also showed the correlation of H-4' with the carbon at 118.9 ppm which was readily assigned to C-7a'. In the similar manner H-5' and H-7' showed the simultaneous correlations with the signal at $153.2 \mathrm{ppm}$ assigned to quaternary C-3a'.

The proton resonance for the secondary amino group showed a three-bond correlation with the signal at $118.9 \mathrm{ppm}$, previously attributed to $\mathrm{C}-7$. Having in mind that the positions through tree bonds in the substituent side of molecule occupy the heteroatoms it's clear that the mentioned carbon belongs to coumarin moiety and attributed to C-3.

\section{Chemistry}


Table 1. NMR data of compound 5 in DMSO- $d_{6}$.

\begin{tabular}{|c|c|c|c|c|}
\hline Position & $\delta_{\mathrm{H}}, \mathbf{m}(J, \mathbf{H z})$ & $\delta_{\mathrm{C}}$ & NOESY $^{a}$ & HMBC $^{\mathrm{b}}$ \\
\hline 2 & & 157.9 & & \\
\hline 3 & & 118.9 & & \\
\hline 4 & & 167.5 & & \\
\hline $4 a$ & & 122.3 & & \\
\hline 5 & $7.91 \mathrm{dd}(8.0,1.6)$ & 126.1 & 6 & $7,8 \mathrm{a}, 4$ \\
\hline 6 & $7.23 \mathrm{td}(8.0,1.2)$ & 123.4 & 5,7 & $4 a, 8$ \\
\hline 7 & $7.50-7.52 \mathrm{~m}$ & 132.6 & 6,8 & $5,8 \mathrm{a}$ \\
\hline 8 & $7.18 \mathrm{dd}(8.4,1.2)$ & 116.5 & 7 & $4 a, 6,8 a$ \\
\hline $\mathbf{8 a}$ & & 152.9 & & \\
\hline N-H & 8.97 brs & & 5 & 3 \\
\hline 2 & & 172.0 & & \\
\hline $3 a^{`}$ & & 153.2 & & \\
\hline 4 & $7.50-7.52 \mathrm{~m}$ & 116.3 & 5 & $6,7 a^{`}$ \\
\hline 5 & $8.18 \mathrm{dd}(8.8,2.4)$ & 123.0 & 4 & $3 a^{\prime}, 6,7$ \\
\hline 6 & & 142.3 & & \\
\hline 7 & $8.77 \mathrm{~d}(2.4)$ & 118.9 & & $3 a^{\prime}, 5,6,7 a^{\prime}$ \\
\hline $7 \mathrm{a}^{\prime}$ & & 129.7 & & \\
\hline
\end{tabular}

aNOESY interactions of the hydrogen from the column "Position" with the corresponding hydrogen from the column "NOESY".

${ }^{\mathrm{b}} \mathrm{HMBC}$ interactions of the hydrogen from the column "Position" with the corresponding carbons from the column "HMBC".

The last two carbon signals at $157.9 \mathrm{ppm}$ and $172.0 \mathrm{ppm}$ in the ${ }^{13} \mathrm{C}$ NMR spectrum (Fig. 7), were attributed to C-2 i C-2', respectively, based on their chemical shifts, since no $\mathrm{H}$ interactions were observed in any of the 2D spectra and by comparison with the analogous signals in the previously studied compounds (Dekić et. al., 2010), (Dekić et. al., 2013).

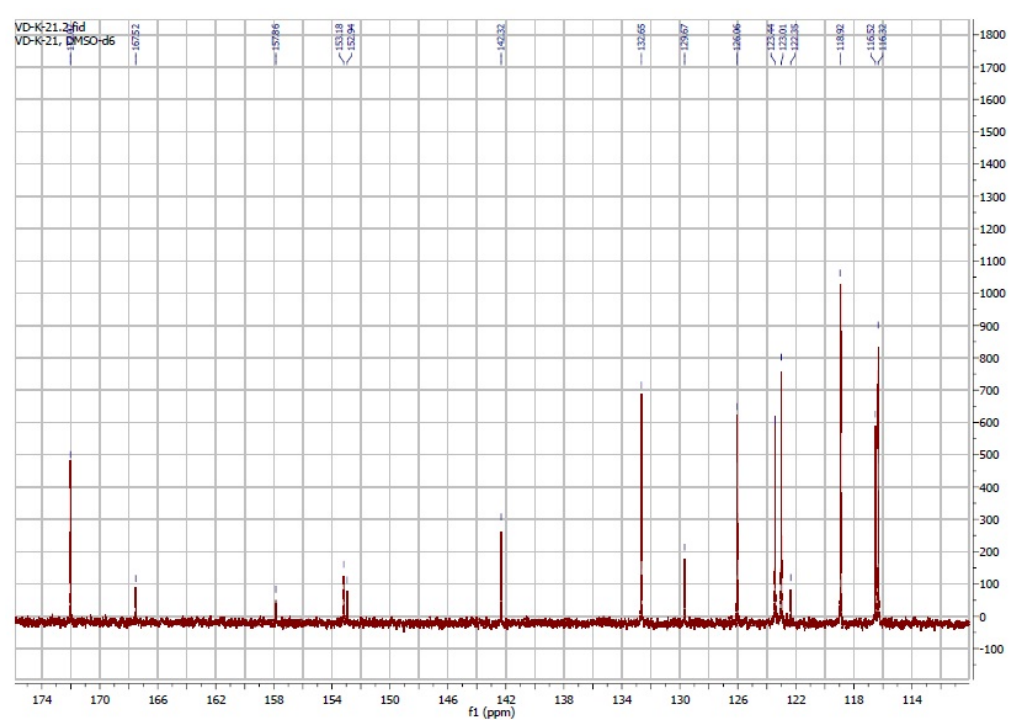

Fig. 7. The ${ }^{13} \mathrm{C}$ NMR spectrum of 3-nitro-4-((6-nitrobenzothiazol-2-yl)amino)-2H-chromen-2-one.

\section{ACKNOWLEDGEMENTS}

This work was supported by the Ministry of Education, Science and Technological Development of Serbia [Project No. 172061, and 45022].

\section{REFERENCES}

Dekić, V., Dekić, B., \& Radulović, N. 2013. ${ }^{1} \mathrm{H}$ and ${ }^{13} \mathrm{C}$ NMR spectral assignments of an amino acidcoumarin hybrid.Facta Universitatis Series: Physics,

\section{Chemistry}


Chemistry and Technology, 11(3), pp. 101-107. doi:10.2298/fupct1301101d

Dekić, V., Radulović, N., Vukićević, R., Dekić, B., Skropeta, D., \& Palić, R. 2010. Complete assignment of the ${ }^{1} \mathrm{H}$ and ${ }^{13} \mathrm{C}$ NMR spectra of antimicrobial 4-arylamino- 3-nitrocoumarin derivatives. Magnetic resonance in chemistry ,48(11), pp. 896-902. pmid:20821411. doi:10.1002/mrc.2681

El-Agrody, A.M., El-Latif, A.M.S., El-Hady, N.A., Fakery, A.H., \& Bedair, A.H. 2001. Heteroaromatization with 4-Hydroxycoumarin part II: Synthesis of some new pyrano[2, 3d]pyrimidines, [1, 2, 4] triazolo[1, 5-c] pyrimidines and pyrimido $[1,6-b]-\left[\begin{array}{lll}1, & 2, & 4\end{array}\right]$ triazine derivatives. Molecules, 6, pp. 519-527.

El-Farargy, A.F. 1991. Synthesis and some reactions of 8-terc-butyl-6-hydroxy-4methylcoumarin. Egyptian Journal of Pharmaceutical Sciences, 32, p. 625.

Emmanuel-Giota, A.A., Fylaktakidou, K.C., Hadjipavlou-Litina, D.J., Litinas, K.E., \& Nicolaides, D.N. 2001. Synthesis and biological evalution of several 3-(coumarin-4-yl) tetrahydroisoxazole and 3-(coumarin-4-yl) dihydropyrazole derivatives. Journal of Heterocyclic Chemistry, 38, pp. 717-722.

Kaljaj, V., Trkovnik, M., \& Stefanović-Kaljaj, L. 1987. Synthesis of new heterocyclocoumarins starting with 3-cyano-4-chlorocoumarin. Journal of the Serbian Chemical Society, 52(4), pp. 183-185.

Kostova, I. 2005. Synthetic and natural coumarins as cytotoxic agents. Curr Med Chem Anticancer Agents, 5(1), pp. 29-46. pmid:15720259
Manolov, I., \& Danchev, N.D. 1995. Synthesis, toxicological and pharmacological assessment of some 4-hydroxycoumarin. European Journal of Medicinal Chemistry, 30, pp. 531-536.

Murray, R.D.H., Mendez, J., \& Brown, S.A. 1982. The natural coumarins: Occurance, chemistry and biochemistry.New York: Wiley \& Sons.

Nofal, Z.M., El-Zahar, M., \& El-Karim, A.S. 2000. Novel coumarin derivatives with expected biological activity.Molecules, 5, pp. 99-113.

O'kennedy, R., \& Thornes, R.D. 1997. Coumarins: Biology, applications and mode of action.Chichester: Wiley \& Sons.

Patonay, T., Litkei, G.Y., Bognar, R., Erdei, J., \& Misztic, C. 1984. Synthesis, antibacterial and antifungal activity of 4-hydroxy-coumarin derivatives, analogues of Novobiocin. Pharmazie, 39, pp. 86-91.

Pratibha, S., \& Shreeya, P. 1999. Synthesis, characterization and antimicrobial studies of some novel 3-arylazo-7-hydroxy-4-methylcoumarin. Indian Journal of Chemistry, 38, pp. 1139-1142.

Raev, L., Voinov, E., Ivanov, I., \& Popov, D. 1990. Antitumor activity of some coumarin derivatives. Pharmazie, 45, pp. 696-698.

Shaker, R.M. 1996. Synthesis and reactions of some new 4H-pyrano [3, 2-c] benzopyran-5-one derivatives and their potential biological activities. Pharmazie, 51, pp. 148-151.

Zahradnik, M. 1992. The production and application of fluorescent brightening agents.Chichester: Wiley \& Sons

\footnotetext{
*E-mail: vidoslav.dekic@pr.ac.rs
} 